\title{
From Curriculum Mapping to Assessment: One Psychology Department's Adventure
}

\author{
Matthew T. Heinly ${ }^{1}$, Anurag Rimzhim ${ }^{2}$, Rebecca A. Boncoddo ${ }^{2} \&$ Carolyn R. Fallahi $^{2}$ \\ ${ }^{1}$ University of Connecticut, Storrs, USA \\ ${ }^{2}$ Central Connecticut State University, New Britain, USA \\ Correspondence: Carolyn R. Fallahi, Department of Psychological Science, Central Connecticut State University, \\ 1615 Stanley Street, New Britain, CT. 06050, USA. Tel: 860-832-3114.
}

Received: October 8, 2018

Accepted: October 24, 2018

Online Published: November 7, 2018

doi:10.5430/irhe.v3n4p12

URL: https://doi.org/10.5430/irhe.v3n4p12

\begin{abstract}
Given the current focus on assessment, funding decisions, and increased demands for faculty accountability, many institutions of higher education and academic departments must demonstrate evidence of student learning. Beginning with a curriculum map, we operationally defined how our learning objectives were met for each course. Using this curriculum map, we then developed a common syllabus for each course, which in turn allowed us to more specifically define course learning objectives and a basic outline of content. This process informed and faciltiated the development of embedded assessments and rubrics for each course. Once data is collected from these assessments, we will refine our assessment battery and determine which learning objectives are being met as well as what courses or curricular modifications are needed. This is an account of one department's assessment process.
\end{abstract}

Keywords: curriculum mapping, common syllabus, assessment, higher education

Faculty in higher education are expected to provide evidence that students are receiving a quality education (Halpern, 1988; Stanny, 2015). "Assessment is essential not only to guide the development of individual students, but also to monitor and continuously improve the quality of programs" (Gardiner, 1994, p. 109). Finding a way to assess whether or not students are receiving a quality education remains challenging. Most colleges and universities participate in accreditation, an evaluative process that compares institutions against a standard of excellence (NEASC, n. d.). Historically, higher education institutions have determined academic standards and curriculum; however, the current trend is to involve state and federal government in those decisions (Eaton, 2010). Furthermore, the allocation of funds by the government has relied on performance-based funding in recent years, necessitating the continual assessment and improvement of our programs (Halpern, 2013). As a result, academic departments within higher education institutions are now charged with the additional task of developing and implementing student learning outcomes (SLOs) and assessing how well they are meeting those outcomes (Halpern, 1988, 2013; Stanny, 2015). This is the dynamic model that one psychology department utilized in order to modify and rework prior departmental assessment guidelines and procedures with the purpose of both habituating the practice of and setting the standard for charting student progress.

\section{Curriculum Recommendations from the American Psychological Association}

To begin our assessment process, we first reviewed the 2013 American Psychological Association's updated goals for an undergraduate major in psychology and APA's recommendations for assessment. APA's goals include: 1) a knowledge base in psychology, 2) scientific inquiry and critical thinking, 3) ethical and social responsibility in a diverse word, 4) communication, and 5) professional development (American Psychological Association [APA], 2013). Reviewing APA's stance on Assessment, we utilized the October 2009 Assessment CyberGuide for learning goals and outcomes, published as a resource for psychology departments to help design and implement assessment plans (Pusateri, 2009). In this document, they ask the question, Why are you doing assessment? Their answer - You have to. You want to.

As such, the mandate to report on assessment initiatives not only derives from university administration and government - both at the state and federal levels - but also from the psychological professional organization as well. 


\subsection{Bloom's and Fink's Taxonomy}

The literature on education, specifically on taxonomies, served as a starting point for our review of our assessment practices. Taxonomies allow educators to classify levels of learning; and as a result, they inform assessment as it helps educators understand the way in which students acquire knowledge and skills (Bloom, Englehart, Furst, Hill, \& Krathwohl, 1956). Coming out of a need for standardized educational goals, Bloom's taxonomy was born. Bloom et al. identified three domains of learning, including cognitive, affective, and psychomotor. Bloom's taxonomy was frequently used as a model for educators to design and redesign courses, provide assessment and measures of learning (Fallahi \& LaMonaca, 2009). Fink (2003) expanded Bloom's taxonomy and included domains that were not traditionally included in existing taxonomies. Both Fink's (2003) and Bloom et al.'s (1956) taxonomies focused on determining the goals of the course or the skills that students would acquire at the close of the semester. Fink (2003) encouraged educators to develop educational goals aligned to taxa and recommended the incorporation of significant learning - as opposed to the traditional view of course content alone - in order to achieve those goals. Wiggins and McTighe (1998) recommended designing curriculum through backwards design. In this model, the desired outcome of student learning and the assessment of that learning are identified and developed; and, only after these two phases have been accomplished does the educator then design instruction. This is accomplished by operationalizing the goals in terms of the assessment.

We reviewed the recommendations of the American Psychological Association's guidelines for the goals of an undergraduate psychology major (APA, 2013) and educational theories (Bloom et al., 1956; Fink, 2003), to formulate a plan of action for reworking our assessment efforts. This new initiative focused on determining the goals of our program, prioritizing the skills and content areas that were essential for students to develop, and then devising a plan to reformat our assessment protocols.

\section{Implementation}

Given the recommendations outlined in the literature, our department began the process of creating a new assessment initiative centered on student learning outcomes. Faculty members connected curriculum to the assessment by first providing an evaluation of our curriculum through the process of curriculum mapping. Curriculum mapping involves delineating the content, learning outcomes, method of instruction, and a framework for assessment (Harden, 2001; Stanny, 2015). We focused on the curriculum's coverage of departmental learning objectives and then added the learning objectives specific to each course. Lastly, we created embedded assessments and rubrics for the courses based on the learning objectives. The following is a detailed description of our process.

\subsection{Curriculum Mapping}

\subsubsection{Conceptual Framework}

One method that has been utilized by a variety of academic departments is to create a map for the entire curriculum, referred to as curriculum mapping. The curriculum map ties learning outcomes and objectives to common departmental assessment (Stanny, 2015). Often times in education, there is an apriori assumption that the information disseminated by the teacher is indeed learned by the student. This is referred to as the "declared" curriculum (Harden, 2001). Harden argues that the declared curriculum may differ from the curriculum actually taught or even learned by the student. The curriculum that is learned is what we measure. Therefore, determining the curriculum map for a department allows the faculty to visualize the curriculum's overall organization and structure, thereby making the curriculum more transparent to both faculty and students. This ensures that the learned curriculum is more in line with what we teach and what we assume students learn.

There are several examples in the literature of the use of curriculum mapping to provide a connection between learning outcomes and instruction. Uchiyama and Radin (2009) discussed the use of a curriculum map within a Teacher Licensure program, and specifically pointed out the flexibility of curriculum maps to align courses in the program with overall departmental learning outcomes. The authors discussed the intention of using the curriculum map to align their curriculum with state standards, but they serendipidously found that the process also increased collegiality and collaboration. Specifically, this process generated discussions of how the faculty worked more closely on how material was covered in classes, and they even worked collaboratively to produce conference presentations about the process. Merritt, Blake, McIntyre, and Packer (2012) have also successfully implemented a curriculum map to organize their Occupational Therapy program. The authors discussed how each of their courses addressed the overall learning objectives defined as essential competencies by one of their professional organizations. Spencer, Riddle, and Knewstubb (2012) utilized a curriculum map to organize their graduate department in Law and Management. Harden's (2001) article summarized the use of a curriculum map to organize the curriculum of a 
medical school. Not only does he discuss the use of a curriculum map within the context of his particular program, but he also discusses more generally the benefit of using curriculum maps to connect curriculum with learning objectives. He points out the distinction between instruction and what is actually learned, and how using a curriculum map can make the connection between the two more transparent. Although these were distinct approaches utilizing different guiding theoretical ideas in diverse content areas, they all completed the process with a better understanding of how their individual departments were addressing their overall learning objectives with their curriculum, and how this allows for better assessment of student learning.

\section{Procedure}

A Psychological Science department in a New England state university started revamping their assessment protocols and began with creating their psychology major curriculum map. As mentioned above, we referenced the APA's Guidelines for the Undergraduate Psychology Major (2013) to create our departmental specific learning objectives, which expanded upon APA's recommendations:

1. Identify, describe, and apply key concepts, principles, and overarching themes in psychology.

2. Interpret, design, and conduct basic and applied research.

3. Demonstrate effective written and oral communication skills in various formats and for various purposes.

4. Examine theories, philosophies, research, and cultures from diverse standpoints including those that do not represent mainstream western perspectives.

5. Apply ethical standards to evaluate psychological science and adopt values that build community at local, national, and global levels.

6. Identify and develop skills and experiences relevant to achieving selected career goals.

The department's faculty members were asked to evaluate the courses they instruct to identify which of the learning objectives their courses meet, keeping in mind that not every course was going to meet all of the learning objectives. However, it was expected (and confirmed by our findings) that across the entire curriculum, all of the learning objectives were met. Thus, the next step was to determine how each individual course addressed the learning objectives. This, we operationally defined, could be done in one of the following three ways:

1. Introduced - The course provides a basic overview of one or more of the goals outlined in the learning outcomes adopted by our department. Coverage of the learning outcome(s) might be cursory or basic, and not advanced to the extent where practice, application or intensive reflection is required.

2. Practiced - The course provides a basic overview of one or more of the goals outlined in the learning outcomes adopted by our department. Coverage of the learning outcome(s) might be basic, yet some practice, repetition, and/or application is required to facilitate students' identification and application of relevant concepts. Intensive reflection about learning experiences is not required.

3. Extensive Practice and Reflection - The course moves beyond a basic introduction to how course material might be used to meet the goals outlined in the learning outcome. Rather, extensive practice and active learning are required. By learning in a hands-on manner, at multiple junctures of the course, the students are required to apply concepts and ideas to real-world problems. In addition, intensive reflection about student experiences during the learning activities and practice experiences is required, as is some consideration of how the active learning experiences are required in the evolving professional world of psychology.

The entire department reviewed the depth of knowledge and skills learned by students across the curriculum and made modifications until there was a consensus. For example, there was significant discussion around which courses were introducing a particular topic. We concluded that introducing a topic meant that it was only learned for the first time in our very beginning psychology classes, e.g. introduction to psychology and lifespan development, both of which are also general education coursework. In addition, the designation of extensive practice and reflection was reserved for those courses where the content and skills had been introduced in prior courses, practiced, and now the student was further developing those skills, e.g. our second research methods course where students develop, run, and analyze and interpret the results from their independent research study, which they designed in the first research method course. Table 1 provides the curriculum map for our undergraduate courses. 
Table 1. Curriculum maps for undergraduate courses that used the Introduction (I), Practice (P) and/or Extensive Practice (EP) levels to achieve Learning Outcomes (LO's)

$\begin{array}{lllllll}\text { Course } & \text { L01 } & \text { L02 } & \text { L03 } & \text { L04 } & \text { L05 } & \text { L06 }\end{array}$

\begin{tabular}{l} 
Course \\
\hline Introduction to Psychology \\
Exploring Psychology \\
Research Methods I \\
Research Methods II \\
Life-Span Development \\
Abnormal Psychology \\
History \& Systems of Psychology
\end{tabular}

Learning \& Memory

Cognitive Psychology

Sensation \& Perception

Social Psychology

Cross-Cultural Psychology

Intergroup Relations

Motivation

Biopsychology

Personality Psychology: Theories \&

Research

Environment \& Behavior

Peace Psychology

Peer Tutoring in Research Methods

Industrial \& Organizational Psychology

Introduction to Health Psychology

The Psychology of Community Service

Psychology \& the Law

Psychology of Early Childhood

Child Psychology

Adolescent Psychology

Adult Development \& Aging

Psychology of the Exceptional Child

Psychology Of Dying and Death

Humanistic Psychology

\section{Wave I Courses (Fall 2015)}

\begin{tabular}{llllll|}
$\mathrm{I}$ & $\mathrm{I}$ & $\mathrm{I}$ & $\mathrm{I}$ & $\mathrm{I}$ & \\
& $\mathrm{I}$ & $\mathrm{I}$ & & & $\mathrm{I}$ \\
$\mathrm{P}$ & $\mathrm{P}$ & $\mathrm{P}$ & & $\mathrm{P}$ & $\mathrm{P}$ \\
$\mathrm{EP}$ & $\mathrm{EP}$ & $\mathrm{EP}$ & & $\mathrm{EP}$ & $\mathrm{EP}$ \\
$\mathrm{I}$ & $\mathrm{I}$ & & $\mathrm{I}$ & $\mathrm{I}$ & $\mathrm{I}$ \\
$\mathrm{P}$ & $\mathrm{P}$ & $\mathrm{P}$ & $\mathrm{P}$ & $\mathrm{P}$ & $\mathrm{P}$ \\
$\mathrm{P}$ & $\mathrm{P}$ & $\mathrm{P}$ & $\mathrm{P}$ & & \\
\hline
\end{tabular}

\section{Wave II Courses (Fall 2016)}

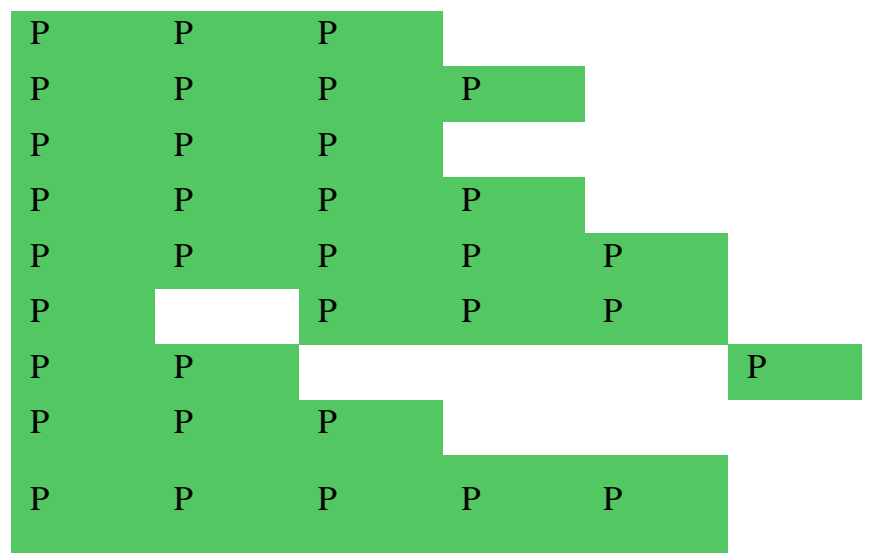

\section{Wave III courses (Fall 2017)}

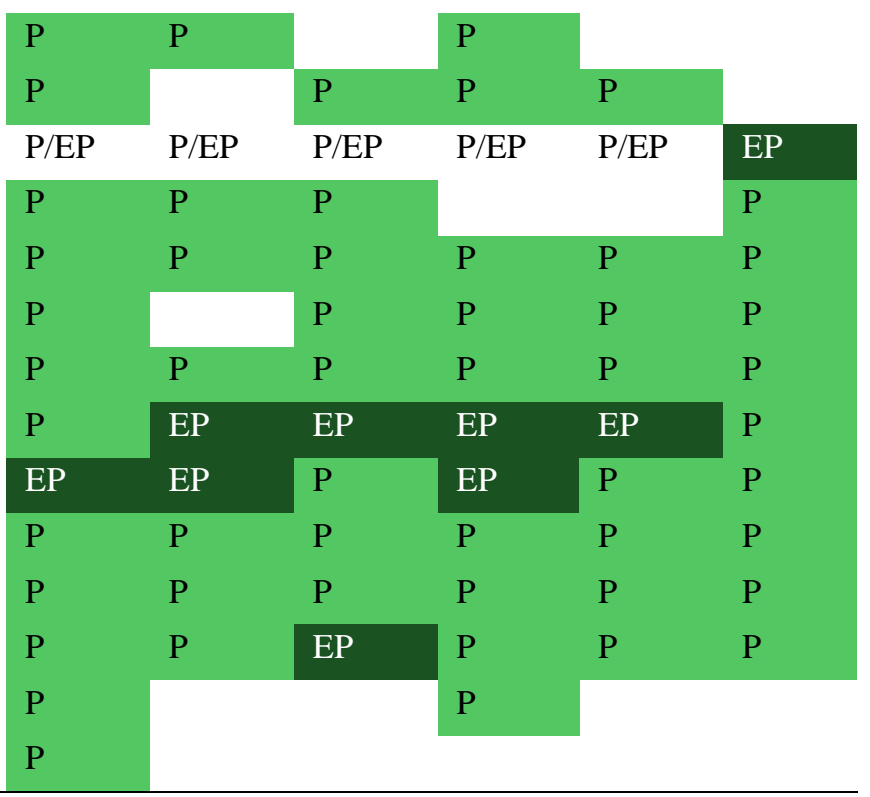




\begin{tabular}{|c|c|c|c|c|c|c|}
\hline Human Sexuality & $\mathrm{P}$ & & & & & \\
\hline Media Psychology & $\mathrm{P}$ & $P$ & $\mathrm{P}$ & $P$ & $\mathrm{P}$ & \\
\hline Positive Psychology & $\mathrm{P}$ & EP & $\mathrm{P}$ & $\mathrm{P}$ & $P$ & $P$ \\
\hline Introduction to Psychotherapy & $\mathrm{EP}$ & $\mathrm{P}$ & $\mathrm{P}$ & EP & EP & EP \\
\hline Psychology of Women & $\mathrm{P}$ & & & $\mathrm{P}$ & & \\
\hline Psychological Evaluation & $\mathrm{P}$ & $\mathrm{P}$ & $\mathrm{P}$ & $\mathrm{P}$ & $\mathrm{P}$ & EP \\
\hline Drugs \& Behavior & $\mathrm{P}$ & & & $\mathrm{P}$ & & \\
\hline Human Neuropsychology & $\mathrm{P}$ & $P$ & $\mathrm{P}$ & $\mathrm{P}$ & $P$ & \\
\hline Behavior Modification: Theory \& Practice & $\mathrm{P}$ & & & & & EP \\
\hline Internship in Psychological Applications & $\mathrm{P}$ & & & $\mathrm{P}$ & EP & EP \\
\hline \multicolumn{7}{|l|}{ Psychology Capstone Seminar } \\
\hline Topics in Psychology & $P$ & & & & & \\
\hline $\begin{array}{l}\text { Independent Reading \& Research in } \\
\text { Psychology }\end{array}$ & $\mathrm{EP}$ & EP & $\mathrm{EP}$ & & EP & $\mathrm{EP}$ \\
\hline
\end{tabular}

Faculty teaching the same courses worked together to determine how the learning objectives were addressed in each individual course. The entire curriculum map was reported to the department as a whole in order to evaluate these criteria. At this stage there were only a few adjustments made, indicating an agreement about the ratings among colleagues teaching the same courses. As our department of psychology demonstrated, a curriculum map is created through a dynamic process, which allows for the possibility of edits and revisions to the curriculum map or to the curriculum to address areas that are deemed to have too little coverage throughout the entire curriculum.

\section{Common Syllabus}

\subsection{Conceptual Framework}

The common syllabus is intended to serve as a unifying document for all instructors of a course, and also to help inform new faculty or adjuncts teaching a course for the first time about the common structure of a course adopted across various sections taught by different instructors (Ueckert, Adams, \& Lock, 2011). One way that a common syllabus has been used effectively was demonstrated by Ueckert, Adams, and Lock (2011), who adopted a common syllabus for an introductory level biology course to improve the "D", "F", and withdrawal rates (DFW) rates. They found that not only was there a decrease in the DFW rate but also an increase in the number of students receiving an "A" or "B" in the course. In an effort to create a more consistent experience across medical schools in the United Kingdom and Ireland, McHanwell et al. (2007) drafted a common syllabus for anatomy courses, which they referred to as a core syllabus. This was a comprehensive outline of all content that should be covered in anatomy courses. Sellani and Harrington (2002) wrote about the difference between online courses and traditional courses, and they discussed the use of common syllabi in their online MBA program. The authors pointed out how common syllabi were used to create a consistent curriculum across courses, and still allowed for flexibility by allowing instructors to include particular content that deviated from the common syllabus' prescribed content.

\subsection{Procedure}

After the curriculum map was created, faculty members teaching the same courses worked together to collaboratively design a common syllabus for the individual courses. The common syllabus contains a brief course description, the curriculum objectives that were outlined on the curriculum map, more specific course objectives, and lastly, a basic topics outline. For our department, the common syllabus served as a point to connect a course to the curriculum map, and also outline the individual learning objectives of the course. It were those individual learning objectives which provided the framework for our embedded assessments and rubrics. See Appendix A as an example of a common syllabus for a low level, entry course and Appendix B for a common syllabus for a higher level junior or senior level course. 


\section{Assessment}

\subsection{Conceptual Framework}

Assessment is recognized as an important piece of departmental evaluation of instruction within psychology and other academic content areas (Halpern, 1988, 2013; Stanny, 2015). To accomplish effective assessment within our department, we progressed from general to specific learning outcomes. We started with the construction of the curriculum map to delineate the coverage of the departmental learning objectives within the context of the entire curriculum. We elaborated on each course by creating a common syllabus that reiterated the overall departmental learning objectives addressed in that particular course, and added more course-specific learning objectives. The last step involved creating integrated assessment instruments which were collaboratively drafted to ascertain the level of student understanding and skills that specifically represent the defined learning outcomes for that particular course. The connective thread throughout this process is student learning outcomes. This approach applies Wiggins and McTighe's (1998) recommendation to approach a curriculum in a backwards fashion that considers outcomes first. The assessment is then an operationalization of learning outcomes. Although Harden (2001) discusses how curriculum maps can be an important tool that improves assessment, we could not find any documentation of a process that actually connects learning outcomes to assessment by using a curriculum map and common syllabi to tie together the curriculum and assessment to address specific student learning outcomes.

\subsection{Procedure}

Getting a commitment from an entire department for assessment is critical. When the curriculum mapping, common syllabi and assessment process was presented to the department, it was pitched specifically as a department generated effort to encourage department ownership of this process. We believed that we were doing a fairly good job with our curriculum, but really did not have hard data to back up that assertion. We were interested in assessing student learning and determining strengths, weaknesses, and, if necessary, creating a corrective plan of action to improve student outcomes. Our goals were not to identify flaws with particular faculty members, but instead, to identify gaps and weaknesses in our curriculum, and address those issues in response to our assessment (Halpern, 1988).

We presented our plan at a faculty departmental meeting, and then scheduled a day long retreat to begin the process of developing the curriculum map. We had another day-long retreat to begin development of the common syllabi. When presenting this process to the department, collaboration and teamwork were emphasized. Faculty who taught a particular course worked within groups to identify clear student learning goals and skills and to articulate how the course addressed the learning outcomes for the purposes of the curriculum map. The same group of faculty members then crafted a common syllabus and created assessment protocols and/or rubrics that measured those operationally defined goals or skills. All faculty, both full- and part-time, were provided an opportunity to participate in this process. While not everyone participated in the development of the common syllabi and assessment protocols, all faculty reviewed them and offered their comments. Departmental assessments are an ongoing and dynamic process, and we hope that we will be able to evaluate what is working and be able to modify and refine assessment protocols as needed. We created appropriate embedded assessments for each course. We decided to approach the assessment piece in three different waves. The first wave included our Required Courses, which were seven courses that all majors must complete to graduate. The courses were PSY 112 Introduction to Psychology (3 credits), PSY 113 Exploring Psychology (1 credit), PSY 221 Research Methods in Psychology I (4 credits), PSY 222 Research Methods in Psychology II (4 credits), PSY 236 Life-Span Development (3 credits), PSY 330 Abnormal Psychology, and PSY 490 History \& Systems of Psychology (3 credits). According to the APA Board of Educational Affairs Task Force on Psychology Major Competencies (2002), there are different assessment techniques that may be better for certain types of courses and content areas being assessed. Given the applied nature of PSY 113, 221, and 222, it was decided that a rubric that evaluated the students' performance on course assignments (including the research proposal and final project in the Research Methods courses) would be most effective. All of the rubrics were to be completed at the conclusion of the semester to reflect the students' overall performance in that course. For the remaining four courses, we used embedded multiple choice assessments. Individual professors teaching each of these courses worked together collaboratively to create assessment questions for that particular course, emphasizing factual, conceptual, and applied questions. After the groups compiled all of the questions to their satisfaction, the assessments were copied and distributed to the professors teaching those courses so that they could be administered at the beginning of the semester. At the end of the semester, copies of the same assessments distributed at the beginning of the semester were once again given to the instructors, so that pre- and post- data could be collected. These were all distributed with Scantron sheets to facilitate quick grading to return the scores back to the professors, because some of the faculty were using the assessment scores as a graded item in their courses. By combining these 
methods across the entire curriculum, we are implementing multiple measures of each learning objective. In addition, we used questions in both our PSY112 course (first year introductory course) and PSY 490 (senior level course) to ascertain improvement and achievement across the curriculum. After one year of assessments, our plan is to conduct an item-analysis, allowing us to update our questions based on item difficulty, item discrimination, reliability, and other factors. If new questions are needed, the faculty teaching a particular course will again reconvene and participate in the development of the new assessment questions.

We have completed this process since the fall 2015 semester. We will continue to conduct this type of assessment for all current and future courses. We will also evaluate the assessment items and use the results to modify and edit the assessments to make them more effective. We also plan to increase the number of classes that will be assessed, including the second wave of assessments, which include our Core Courses (nine courses across four different categories). For each of these future waves, we will facilitate the assessment creation process by implementing the same procedure of creating common syllabi for those courses, and then using the common syllabi as a springboard for assessment creation. In this way, we are using the learning outcomes as the basis of assessment creation in line with Wiggins and McTighe's (1998) recommendations. We have also already created a curriculum map for our graduate program and will be attempting to create common syllabi and assessments for those courses in the coming semesters.

\section{Conclusion}

Assessment is part of university and institutional culture. It is mandatory for all departments to assess their programming as it relates to student learning and program goals (Stanny, 2015). Given the climate of budget concerns, departments may have to demonstrate their value through assessment. The departments' main purpose is to provide educational curriculum for its students, while departments are simultaneously tasked with determining course coverage, hiring decisions, and serving the university as a whole. The decisions made by departments can be likened to military decisions which happen on a tactical or strategic level. Departments' tactical decisions are made one or two semesters ahead of time and tend to focus on making sure that there are enough sections of courses available at specific times. Strategically, departments must collectively work towards being a productive department that meets both university and departmental goals and fulfills general education needs. In addition, departments are expected to produce employable graduates and present a curriculum that provides graduates with competence in understanding and applying knowledge and concepts, but who also have a particular skill set related to the departmental academic discipline. Assumptions may be made that the curriculum provided accomplishes these goals (Harden, 2001). However, without proper assessment, this remains an assumption.

We outlined one department's assessment initiative and provided a summary of the exact steps needed to create and implement embedded assessment and rubrics within and across the curriculum. What we have outlined in this paper is an attempt to organize and align departmental curriculum and assessment. This process starts with the overall vision of the department's curriculum embodied in the curriculum map (Harden, 2001; Stanny, 2015). Each course is connected to the overall curriculum and is detailed in terms of learning outcomes and content coverage by drafting an individual common syllabus for each and every course (McHanwell et al., 2007; Sellani \& Harrington, 2002; Ueckert, Adams, \& Lock, 2011). These learning outcomes and conceptual outlines serve as the impetus for creating effective assessment instruments or rubrics to evaluate student learning by working backwards from learning objectives to the specific assessment questions (Fink, 2003; Wiggins \& McTighe, 1998). Finally, this assessment information should be revisited by the department and faculty teaching individual courses for the purpose of determining our strengths within the program and the course, and specific weaknesses that warrant curriculuar changes (Halpern, 1988; Stanny, 2015). This affords the necessary stakeholders the opportunity for remediation of the course, possible consideration of redesign opportunities, or the addition of supportive mechanisms to aid in student learning. Of importance, we do not see this as an opportunity to assess individual faculty, but to work collectively with all instructors.

This assessment strategy is a malleable process that allows for variation and also the possibility of adjustments and modifications to the curriculum or assessment instruments. We do not see this as a once and done attempt but rather as an ongoing process that will be flexible and cyclical in the sense that curriculum changes affect assessment procedures, and assessment can inform curriculum decisions of the department (Halpern, 1988; Stanny, 2015). All of these efforts are achieved best by collaboration and teamwork from the department members. There is a need for documentation, dissemination, and work towards best practices in all of our curriculum. In a perfect world, faculty, administration and students are all stakeholders, by having a greater understanding of how the curriculum works, the connection between learning goals and learning outcomes becomes more firmly established. 


\section{Acknowledgement}

Thank you to Sara R. Fallahi for editing this manuscript, and thank you to the entire department for their effort, persistence, and patience.

\section{References}

American Psychological Association. (2013). APA guidelines for the Undergraduate Psychology Major. Version 2.0. Retrieved from http://www.apa.org/ed/precollege/about/psymajor-guidelines.pdf

Bloom, B. S., Englehart, M. D., Furst, E. J., Hill, W. Hl, \& Krathwohl, D. R. (1956). Taxonomy of educational objectives: The classification of educational goals. New York: David McKay Company.

Eaton, J. S. (2010). Accreditation and the federal future of higher education. Academe, 96(5), 21-24. Retrieved from https://www.aaup.org/article/accreditation-and-federal-future-higher-education\#

Fallahi, C. R., \& LaMonaca, F. H. (2009). The evolution of educational objectives: Bloom's taxonomy and beyond. Journal on Excellence in College Teaching, 20(1), 71-86. Retrieved from https://eric.ed.gov/?id=EJ883718

Fink, L. D. (2003). Creating significant learning experiences: An integrated approach to designing college courses. San Francisco, CA: Jossey-Bass.

Gardiner, L. F. (1994). Redesigning higher education: Producing dramatic gains in student learning (Report No. ASHE-ERIC 7). Washington, D. C.: Office of Educational Research and Improvement (ED). (ED394442). Retrieved from https://eric.ed.gov/?id=ED394442

Halpern, D. F. (1988). Assessing student outcomes for psychology majors. Teaching of Psychology, 15, 181-186. https://doi.org/10.1207/s15328023top1504_1

Halpern, D. F. (2013). A is for assessment: The other scarlet letter. Teaching of Psychology, 40(4), 358-362. https://doi.org/10.1177/0098628313501050

Harden, R. M. (2001). AMEE Guide No. 21: Curriculum mapping: A tool for transparent and authentic teaching and learning. Medical Teacher, 23(2), 123-137. https://doi.org/10.1080/01421590120036547

McHanwell, S., Davies, D. C., Morris, J., Parkin, I., Whiten, S., Atkinson, M., ... Wilton, J. (2007). A core syllabus in anatomy for medical students - Adding common sense to need to know. European Journal of Anatomy, 11(Supplement 1), 3-18. Retrieved from http://eurjanat.com/web/paper.php?id=07S10003

Merritt, B. K., Blake, A. I., McIntyre, A. H., \& Packer, T. L. (2012). Curriculum evaluation: Linking curriculum objectives to essential compentencies. Canadian Journal of Occupational Therapy, 79(3), 175-180. https://doi.org/10.2182/cjot.2012.79.3.7

New England Association of Schools and College Committee on Public Secondary Schools (n. d.). The meaning and value of accreditation. Retrieved from https://cpss.neasc.org/about-accreditation/meaning-and-value

Pusateri, T. (2009). The assessment cyberguide for learning goals and outcomes (2nd ed.). Washington, DC: $\begin{array}{llll}\text { American } & \text { Psychological } & \text { Association. }\end{array}$ http://www.apa.org/ed/governance/bea/assessment-cyberguide-v2.pdf

Sellani, R. J., \& Harrington, W. (2002). Addressing administrator/faculty conflict in an academic online environment. The Internet and Higher Education, 5(2), 131-145. https://doi.org/10.1016/S1096-7516(02)00090-8

Spencer, D., Riddle, M., \& Knewstubb, B. (2012). Curriculum mapping to embed graduate capabilities. Higher Education Research \& Development, 31(2), 217-231. https://doi.org/10.1080/07294360.2011.554387

Stanny, C. J. (2015). Assessing the psychology curriculum: A primer for faculty and administrators. In D. S. Dunn (Ed.), The Oxford handbook of undergraduate psychology education (pp. 813-831). New York, NY: Oxford University Press.

Uchiyama, K. P., \& Radin, J. L. (2009). Curriculum mapping in higher education: A vehicle for collaboration. Innovative Higher Education, 33, 271-280. https://doi.org/10.1007/s10755-008-9078-8

Wiggins, G., \& McTighe, J. (1998). Understanding by design. Alexandria, VA: Association for supervision and curriculum development. Retrieved from http://www.sedl.org/cgi-bin/mysql/picbib-output.cgi?searchuniqueid=171 


\section{Appendix A \\ PSY 112 - Introduction to Psychology \\ Course Description}

Survey of the scientific study of mental processes and behavior.

\section{Curriculum Objectives}

1. Introduce: Identify, describe, and apply key concepts, principles, and overarching themes in psychology. (LO1)

2. Introduce: Interpret, design, and conduct basic and applied research. (LO2)

3. Introduce: Examine theories, philosophies, research, and cultures from diverse standpoints including those that do not represent mainstream western perspectives. (LO4)

4. Introduce: Apply ethical standards to evaluate psychological science and practice and adopt values that build community at local, national, and global levels. (LO5)

\section{Course Objectives}

1. Identify and explain fundamental concepts, principles, and theories in psychological science.

2. Explain how the scientific method is used in studying behavior and mental processes.

3. Apply biopsychosocial principles, concepts, and theories to understand ourselves and others.

4. Describe how ethical standards influence psychological research and practice.

\section{Topics Outline}

I. Theory and research representing content from each of the following general six domains:
A. COGNITIVE processes, memory, perception, learning
B. PERSONALITY and SOCIAL processes, individual differences, psychometrics
C. BIOLOGICAL processes, sensation, neuroscience, consciousness, motivation
D. DEVEOPMENTAL changes in behavior and mental processes across the life span

E. MENTAL and PHYSICAL HEALTH, psychopathology, treatment and health

F. SOCIOCULTURAL processes, diversity, intergroup processes and cross-cultural contexts

II. The history of psychology

III. Methods of psychology/scientific methodology; experiential participation in research activities

IV. Relevant levels of analysis: (e.g., cellular, individual, group/systems, and society/culture)

V. One or more overarching theme, persistent question, or enduring conflict in the field, such as:
A. The interaction of heredity and environment
B. Variability and continuity of behavior and mental processes within and across species
C. Free will versus determinism
D. Subjective versus objective perspective
E. The interaction of mind and behavior
F. Applicability of theories and measures across societal and cultural groups

VI. Relevant ethical issues

VII. We encourage coverage from among the wealth of additional topics and applications across the broad spectrum of psychology and psychological science. This might include (but is not limited to): Identification and development of skills and experiences relevant to achieving selected career goals; identification of the different roles that psychologists can have within the many subfields of the discipline; discussion of additional topics from the six domains above; discussion of additional relevant topics. These additional topics and applications are to be determined by the individual course instructor. We encourage integration that ties together the different areas of psychology to construct a coherent whole story of contemporary psychology. 


\section{Appendix B \\ PSY490 - History \& Systems of Psychology Course Description}

Historical study with emphasis on general philosophical bases, development of psychology as an experimental science, and comparative analysis of principal modes of psychological inquiry.

\section{Curriculum Objectives}

1. Practice: identify, describe, and apply key concepts, principles, and overarching themes in psychology.

2. Practice: interpret, design, and conduct basic and applied research.

3. Practice: demonstrate effective written and oral communication skills in various formats and for various purposes.

4. Practice: examine theories, philosophies, research, and cultures from diverse standpoints including those that do not represent mainstream western perspectives.

\section{Course Objectives}

1. To demonstrate knowledge of the development of systems and theories in psychology and to formulate hypotheses regarding their influences on modern psychological thought.

2. To demonstrate an understanding of the contributions to psychology made by each of the prominent historical systems during the period of its greatest influence.

3. To demonstrate an appreciation of the tentative nature of any system or theory, especially during the present period of development in psychology.

4. To demonstrate an understanding of how historical theories and systems have impacted modern theory and practice.

5. To demonstrate some insight into the possible directions that psychology will take in the future.

\section{Topics Outline}

I. Philosophical roots

II. Biological roots

III. Psychophysical roots

IV. Early Science of Psychology

V. Structuralism

VI. Functionalism

VII. Behaviorism

VIII. Psychoanalysis

IX. Cognitive/Gestalt 